\section{Instant Detoxification of Heroin with High Dose of Buprenorphine}

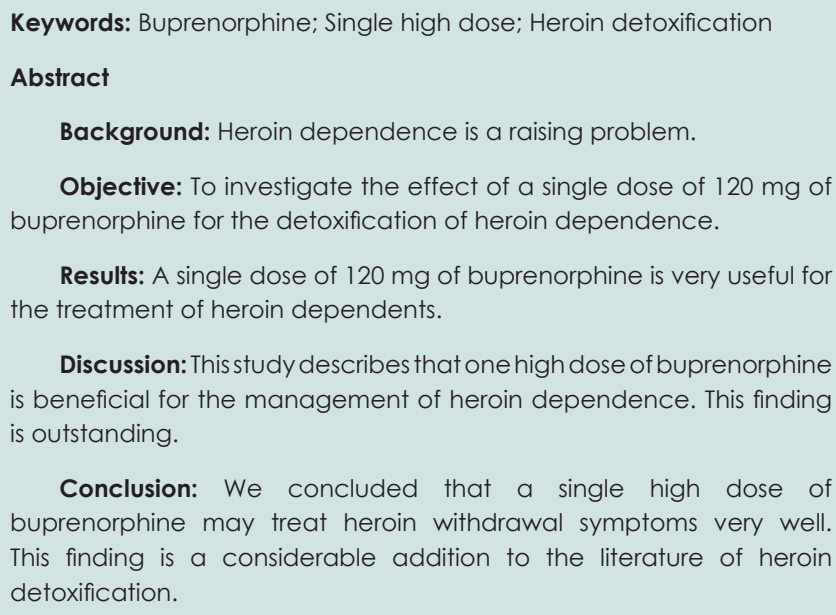

Results: A single dose of $120 \mathrm{mg}$ of buprenorphine is very useful for the treatment of heroin dependents.

Discussion: This study describes that one high dose of buprenorphine is beneficial for the management of heroin dependence. This finding is outstanding.

Conclusion: We concluded that a single high dose of buprenorphine may treat heroin withdrawal symptoms very well. This finding is a considerable addition to the literature of heroin detoxification.

\section{Introduction}

Heroin is a derivative of morphine that was originally considered as a non-addictive derivative of morphine [1].

Buprenorphine was accepted for the treatment of detoxification of heroin and pain. Buprenorphine is a safe medication and a partial $\mathrm{mu}$ receptor agonist with low possibility of overdose [1].

For the detoxification of heroin, buprenorphine is more effective than methadone [2-4]. Researchers such as Johnson, Jaffe, and Fudala reported that $8 \mathrm{mg} / \mathrm{d}$ of buprenorphine is comparable to $60 \mathrm{mg}$ of methadone regarding retention rates and opioids negative urines [5].

Administration of buprenorphine can reduce the incidence of HIV and other related disorders coming after opioids abuse [1,6-8].

Opium and its derivatives have been considered as medicine for a long time in some countries $[9,10]$. Currently, mental disorders are raising globally [11-15]. Considering mental disorders, substance induced disorders, especially opioid derivatives have been known as ascending dilemma. At present, stimulants abuse and stimulants related disorders are a growing problem that have resulted more referral to addiction centers [16-38].

We are now applying a single dose of $120 \mathrm{mg}$ of sublingual buprenorphine for the heroin detoxification.

To the authors knowledge we cannot find published studies on this matter; hence, our study may result to a substantial finding.

According to DSM-5 criteria, we prepared a reliable and valid scale to assess heroin withdrawal pain and craving including grades from 0 to 10 ( 0 means no pain or craving at all and 10 means severe pain or desire all the time) [19-21].

\section{Journal of}

\section{Addiction \& Prevention}

\author{
Jamshid Ahmadi* \\ Substance Abuse Research Center, Department of Psychiatry, \\ Shiraz University of Medical Sciences, Iran \\ *Address for Correspondence \\ Jamshid Ahmadi, Professor and Founding Director, Substance Abuse Research \\ Center, Department of Psychiatry, Shiraz University of Medical Sciences, Shiraz, \\ Iran, Tel/Fax: +98-71-3627 93 19; E-mail: Jamshid_Ahmadi@yahoo.com
}

Submission: 08 February, 2016

Accepted: 16 February, 2016

Published: 20 February, 2016

Copyright: (๑) 2016 Ahmadi J. This is an open access article distributed under the Creative Commons Attribution License, which permits unrestricted use, distribution, and reproduction in any medium, provided the original work is properly cited.

Reviewed \& Approved by: Dr. Thomas Heffernan, Department of Psychology and Faculty of Life and Health Sciences, Northumbria University, UK

Pain and Craving Scale of measurement: 0-1-2-3-4-5-6-7-8-9-10.

\section{Patient description}

Now we illuminate our patient with heroin dependence that was detoxified with a single high dose of $120 \mathrm{mg}$ of buprenorphine.

He was a married 39 year old self employed with middle school education. He lived with his family in Zarghan city of Fars province in south of Iran.

He started smoking opium and abusing benzodiazepines since 15 years prior to admission. He began smoking heroin since 2 years prior to admission. Patient had occasionally been using methamphetamine, tramadol and methadone. He gradually developed anxiety, depressed mood, and insomnia. Since a couple of weeks prior to admission his symptom were increased and was admitted in psychiatric ward.

During precise psychiatric interview and examination, he had opioid withdrawal symptoms, depressed mood, anxiety and insomnia. In physical and neurological examinations we could not find any abnormal abnormality.

Urine drug screening tests was positive for morphine, methadone and benzodiazepine. Serology tests for viral markers (HIV, HCV and $\mathrm{HB} \mathrm{Ag}$ ) were normal.

According to DSM-5 criteria and detailed medical, psychiatric, and substance use history he was diagnosed as "opioid related depressive disorder and opioid (heroin) dependence.

At the time of admission he was complaining of anxiety, insomnia and opioid withdrawals especially pain. We administered olanzapine $20 \mathrm{mg} / \mathrm{d}$ for the treatment of insomnia, and. Anxiety.

On the night of admission (few hours after admission) his pain score was 10 . In the second day of admission, since he was still complaining of severe pain, we administered $120 \mathrm{mg}$ of sublingual buprenorphine as a single dose only. 
Out of 10 , the mean scores of heroin withdrawal pain for 5 days of admission was 10 (the day before buprenorphine administration), and after buprenorphine were 7.7, 3.7, 3 and 3 respectively.

Based on the interview, close monitoring, and precise measurement ( 3 times a day) for heroin withdrawal pain and craving, he reported a rapid declining level of pain and craving after receiving a single dose of $120 \mathrm{mg}$ of buprenorphine.

After 5 days of hospital admission, patient was discharged without any significant withdrawal symptoms.

\section{Discussion}

In Iran substances, such as marijuana, hashish, cocaine, methamphetamine, hallucinogens, alcohol, heroin, opium, morphine and alcohol are illegal (tobacco products are legal).

Opioids dependents are commonly detoxified or treated with clonidine, methadone, and sometimes with buprenorphine.

This study indicates that buprenorphine $120 \mathrm{mg}$ as a single high dose only, is quite effective in the treatment of heroin withdrawal symptoms. Hence our finding may be an outstanding addition to the literature.

\section{Conclusions}

We can conclude that administration of a single high dose of 120 $\mathrm{mg}$ of buprenorphine could completely manage heroin withdrawal symptoms.

It appears that buprenorphine is quite effective in the detoxification of heroin.

\section{References}

1. Sadock BJ, Sadock BJ, Sadock VA, Ruiz P (2015) Kaplan \& Sadock's synopsis of psychiatry: behavioral sciences/clinical psychiatry. Lippinott Wiliams and Wilkins, Philadelphia, USA.

2. Jasinski DR, Pevnick JS, Griffith JD (1978) Human pharmacology and abuse potential of the analgesic buprenorphine: a potential agent for treating narcotic addiction. Arch Gen Psychiatry 35: 501-516.

3. Ling W, Charuvastra C, Collins JF, Batki S, Brown LS Jr, et al. (1998) Buprenorphine maintenance treatment of opiate dependence: a multicenter, randomized clinical trial. Addiction 93: 475-486.

4. Ling W, Rawson RA, Compton MA (1994) Substitution pharmacotherapies for opioid addiction: from methadone to LAAM and buprenorphine. J Psychoactive Drugs 26: 119-128.

5. Strain EC, Stitzer ML, Liebson IA, Bigelow GE (1994) Comparison of buprenorphine and methadone in the treatment of opioid dependence. Am J Psychiatry 151: 1025-1030.

6. Johnson RE, Jaffe JH, Fudala PJ (1992) A controlled trial of buprenorphine treatment for opioid dependence. JAMA 267: 2750-2755.

7. Lewis JW (1985) Buprenorphine. Drug Alcohol Depend 14: 363-372.

8. Jasinski DR, Fudala PJ, Johnson RE (1989) Sublingual versus subcutaneous buprenorphine in opiate abusers. Clin Pharmacol Ther 45: 513-519.

9. Brian J (1994) Opium and infant-sedation in $19^{\text {th }}$ century England. Health Visit 67: 165-166.

10. Jonnes $\mathrm{J}$ (1995) The rise of the modern addict. Am J public Health 85: 11571162.

11. Pridmore S, Ahmadi J (2015) Psalm 137 and Middle cerebral artery infarction ASEAN J Psychiatry 16.
12. Pridmore S, Ahmadi J (2005) Status anxiety. Aust N Z J Psychiatry 39: 205206.

13. Pridmore S, Ahmadi J, Evenhuis M (2006) Suicide for scrutinizers. Australas Psychiatry 14: 359-364.

14. Ahmadi J, Ahmadi N, Soltani F, Bayat F (2014) Gender differences in depression Scores of Iranian and german medical students. Iran J Psychiatry Behav Sci 8: 70-73.

15. Mackay-Smith M, Ahmadi J, Pridmore S (2015) Suicide in shooting galleries. ASEAN J Psychiatry 16.

16. Khademalhosseini Z, Ahmadi J, Khademalhosseini M (2015) Prevalence of smoking, and its relationship with depression, and anxiety in a sample of Iranian high school students. Enliven: Pharmacovigil Drug Saf 1: 005.

17. Ahmadi J, Ghafoori F, Rahimi S (2015) Management of heroin addiction with baclofen and clonidine. Int J Res Rep 1: 1-5.

18. Ahmadi J, Sahraian A, Shariati S (2015) Homicidal patient with major depressive disorder companion with opium dependence: a new arcade. Int J Res Rep 1: 1-5.

19. Ahmadi $\mathrm{J}$ (2015) The effect of buprenorphine and bupropion in the treatment of methamphetamine dependency and craving. Br J Med Med Res 10: 1-4.

20. Ahmadi J (2015) Heroin dependency treatment: a new approach. J Addict Depend 1: 1-3.

21. Ahmadi J, Sahraian A, Dastgheib SA, Moghimi- Sarani E, Bazrafshan A (2015) Treatment of heroin abuse. Sch Acad J Biosci 3: 966-968.

22. Ahmadi $J$ (2015) Hashish-induced olfactory hallucination: A novel finding. J Psychiatry 18: 330.

23. Ahmadi J (2015) Excellent outcome intractable psychosis induced by methamphetamine intoxication after 20 sessions of electro convulsive therapy. J Addict Depend 1: 1-2.

24. Ahmadi J, Ekramzadeh S, Pridmore S (2015) Remission of methamphetamineinduced withdrawal delirium and craving after electroconvulsive therapy. Iran J Psychiatry Behav Sci 9: e1793.

25. Ahmadi J, Sahraian A, Dastgheib SA, Mani A, Mowla A, et al. (2015) ECT and methamphetamine psychosis. Int J Med Pharm Sci 7: 51-53.

26. Ahmadi J (2015) Tramadol dependency treatment: a new approach. J Addict Med Ther Sci 1: 041-043.

27. Ahmadi J, Dehghanian I, Razeghian Jahromi L (2015) Poly substance induced psychosis. Sch J App Med Sci 3: 2693-2695.

28. Ahmadi J, Dehghanian I, Razeghian Jahromi L (2015) Substance induced disorder. Sch J App Med Sci 3: 2700-2703.

29. Ahmadi J, Pridmore S, Ekramzadeh S (2015) Successful use of electro convulsive therapy in the management of methamphetamine induced psychosis with onset during intoxication. J Addict Depend 1: 1-2.

30. Ahmadi J, Dastgheib SA, Mowla A, Ahmadzadeh L, Bazrafshan A, et al. (2016) Treatment of methamphetamine induced persistent psychosis. J Add Pre Med 1: 103.

31. Ang-Lee K, Oreskovich MR, Saxon AJ, Jaffe C, Meredith C, et al. (2006) Single dose of 24 milligrams of buprenorphine for heroin detoxification: an open-label study of five inpatients. J Psychoactive Drugs 38: 505-512.

32. Kutz I, Reznik V (2001) Rapid heroin detoxification using a single high dose of buprenorphine. J Psychoactive Drugs 33: 191-193.

33. Anvar-Abnavi M, Ahmadi J, Hamidian S, Ghafaripour S (2016) Female sexual dysfunction among the wives of opioid-dependent males in Iran. Int $\mathrm{J}$ High Risk Behav Addict 5: e25435.

34. Ahmadi J, Sahraian A, Shariati S, Kazerooni FG, Mehdipour Z, et al. (2015) Delusional disorder joined with opium dependence. Sch J App Med Sci 3: 3387-3390.

35. Ahmadi J, Khoddaman AR, Kordian S, Pridmore S (2016) Treatment of an 
obese opioid dependent with a single dose of $80 \mathrm{mg}$ of buprenorphine: a new opening. Int J Res Rep 2: 11-18.

36. Ahmadi J, Ahmadi F, Torabi A, Ahmadi S, Ahmadi F (2016) A single dose of $55 \mathrm{mg}$ of buprenorphine for the treatment of heroin dependence: a new result. J Harmoniz Res Med and HIth Sci 3: 01-07.
37. Ahmadi $\mathrm{J}$ (2016) Methylphenidate in the treatment of methamphetamine withdrawal Craving: a novel outcome. J Drug Abuse 2: 12.

38. Ahmadi J (2016) Misuse of tablets of ephedrine, adult cold and cold stop to get high: a distinguished enigma. Int J Res Rep 2: 30-35. 